\title{
Aiming for Sustainability and Scalability: Community Engagement in Forest Payment Schemes
}

\author{
Laura F. Kowler ${ }^{1}$, Arun Kumar Pratihast $2,3, * \mathbb{C}$, Alonso Pérez Ojeda del Arco ${ }^{1}$, Anne M. Larson ${ }^{1}$, \\ Christelle Braun ${ }^{2}$ and Martin Herold ${ }^{2}$ \\ 1 Center for International Forestry Research (CIFOR), c/o CIP, Av. La Molina 1895, La Molina, Lima 12, Peru; \\ lkowler3@gmail.com (L.F.K.); alonso.perez.ojedadelarco@gmail.com (A.P.O.d.A.); \\ a.larson@cgiar.org (A.M.L.) \\ 2 Laboratory of Geo-information Science and Remote Sensing, Wageningen University and Research, \\ P.O. Box 47, NL-6700 AA Wageningen, The Netherlands; brauncch@gmail.com (C.B.); \\ martin.herold@wur.nl (M.H.) \\ 3 Wageningen Environmental Research, Wageningen University and Research, P.O. Box 47, \\ NL-6700 AA Wageningen, The Netherlands \\ * Correspondence: arun.pratihast@wur.nl; Tel.: +31-617861457
}

Received: 3 March 2020; Accepted: 10 April 2020; Published: 15 April 2020

\begin{abstract}
Community-based forest monitoring is seen as a way both to improve community engagement and participation in national environmental payment schemes and climate mitigation priorities and to implement reducing emissions from deforestation and forest degradation and foster conservation, sustainable management of forests and enhancement of forest carbon stocks in developing countries (REDD+). There is a strong assumption among community-based monitoring advocates that community monitoring is a desirable approach. However, it is unclear why community members would want to participate in their own surveillance or be involved in a program likely to limit livelihood uses of forest areas and possibly even sanction them based on the data provided. This paper explores these issues by examining three communities involved in Peru's Conditional Direct Transfer Program, in which indigenous communities are compensated for protecting communal forests through various mechanisms, including forest monitoring. The case studies focus specifically on communities that received smartphones and were trained in their use for monitoring. The results affirm the importance that benefits outweigh the costs of local participation to sustain motivation. They also point to key factors supporting the legitimacy of the program, specifically to overcome historical tensions between the state and indigenous communities. These include the nature of engagement by program implementers and the importance of building trust over time.
\end{abstract}

Keywords: REDD+; payments for environmental services; MRV; community-based monitoring; Conditional Direct Transfer Program; legitimacy; sustainability

\section{Introduction}

Payments for environmental services set the stage for involving local communities in conservation by incentivizing behaviors through compensation. Reducing emissions from deforestation and forest degradation and fostering conservation, sustainable management of forests and enhancement of forest carbon stocks in developing countries (REDD+) builds upon this mechanism with the aim of climate change mitigation, sustainable forest management, biodiversity conservation, and poverty alleviation [1,2]. In the international arena, REDD+ is based on the notion of results-based finance at the country level [3-5]. The assessment of results requires an accurate, reliable, and transparent national forest monitoring system (NFMS) to perform MRV that meets international standards. 
Community-based monitoring (CBM) has gained wider application over time in REDD+ implementation. The emphasis to date has been mainly on community engagement, focusing on both technical feasibility (data collection, quality assessment, and interoperability of CBM data) [5-7] and governance questions (linking to existing institutions, capacity building, and benefit-sharing) [6,8-10]. Less attention has been paid to local motivations for community monitoring; in other words, why communities would want to engage in such activities [11-13]. In fact, the reasons to avoid such activities seem more apparent. Community monitoring takes place in a particular historical sociopolitical and cultural context, shaped by past relations between communities and the state [14]. Indigenous communities, in particular, have often been marginalized and even oppressed by the state [14-17], and not all peoples or communities choose to become subjects of a nation $[18,19]$. Historically, the state has dispossessed indigenous peoples of their land [20], forced them out of declared conservation areas [21], and implemented excessive regulations to control land use [22]. Facilitating monitoring and thus greater state oversight of a community's forest use would, therefore, appear to run counter to community interests. Why would indigenous communities want to make it easier for themselves to be monitored?

This article examines the operational feasibility of CBM based on the study of three communities participating in Peru's Conditional Direct Transfer program (TDC, for its abbreviation in Spanish), implemented by the National Forest Conservation Program (PNCB, for its abbreviation in Spanish [23]), which aims to conserve 54 million hectares of forest by 2021. The PNCB intervention emerged after violent conflicts between indigenous protesters and the police in Bagua in 2009. The PNCB is responsible for designing, establishing, implementing, and monitoring national environmental policy, and has taken the lead role in preparing the country for the implementation of REDD+ in coordination with multiple multilateral agencies since 2010. The TDC program is separate from the REDD+ program, although they both are connected to the NFMS. The TDC compensates indigenous communities to protect a portion of their territory that is threatened by deforestation by establishing a conservation area. It began as a five-year program in 2011 and was extended in December 2016. In 2017, the PNCB received funding to involve 100 additional communities in a three-year program that aims to achieve what the former communities were expected to achieve in five years. These communities will receive both financial and technical support.

The analysis in this article employs a multilevel governance approach [23-27], which considers the increased role of non-state actors in decision making, the coordination among actors, the transparency of information, and the capacities necessary to engage in multilevel processes $[23,24,28]$. Several authors argue that emerging horizontal and vertical networks represent new opportunities for diverse actors to participate and coordinate in decision making on natural resources, thus providing for more effective policies $[24,25,29]$. Cross-level coordination or vertical integration is expected to result in locally appropriate and effective actions that improve the fit between local institutions and environmental conditions [30]. Furthermore, the actual engagement of actors across levels, especially local actors, may increase the legitimacy and, subsequently, the environmental effectiveness of policy [31]. Nevertheless, having more actors and levels does not automatically improve participation or results [32].

The objective of this study is first to understand and assess the multilevel governance structure that underpins the forest monitoring system in Peru. We also aim to identify the drivers of deforestation and how they relate to the motivation and obstacles for communities to participate in the scheme, and, more generally, to understand the conditions under which communities support CBM and wish to engage in it. Finally, we identify the contributing and limiting factors to the potential scalability of CBM to Peru's national forest monitoring system. 


\section{Materials and Methods}

\subsection{Site Selection and Case Study Description}

The three communities involved in this study-Puerto Ocopa, Loma Linda Laguna and San Pedro de Pichanaz-are located in the central Peruvian Amazon in the regions of Junín and Pasco (Figure 1; details of the study locations and web-based forest monitoring system can also be accessed at http://www.cbmperu.wur.nl/). The three communities were selected by the PNCB based on priorities associated with the TDC program and were among the highest performing communities at the time of the research. Here, "performance" is understood as those communities that were most effective at monitoring and engaging in the TDC program; PNCB saw them as the most likely to adopt the handheld technology effectively. As a result, the selection of case studies is not representative of the many communities involved in the TDC program; rather, the challenges are likely to be greater elsewhere. The results also provides insights into ways in which the state could work to overcome historical tensions with other indigenous communities in Peru.

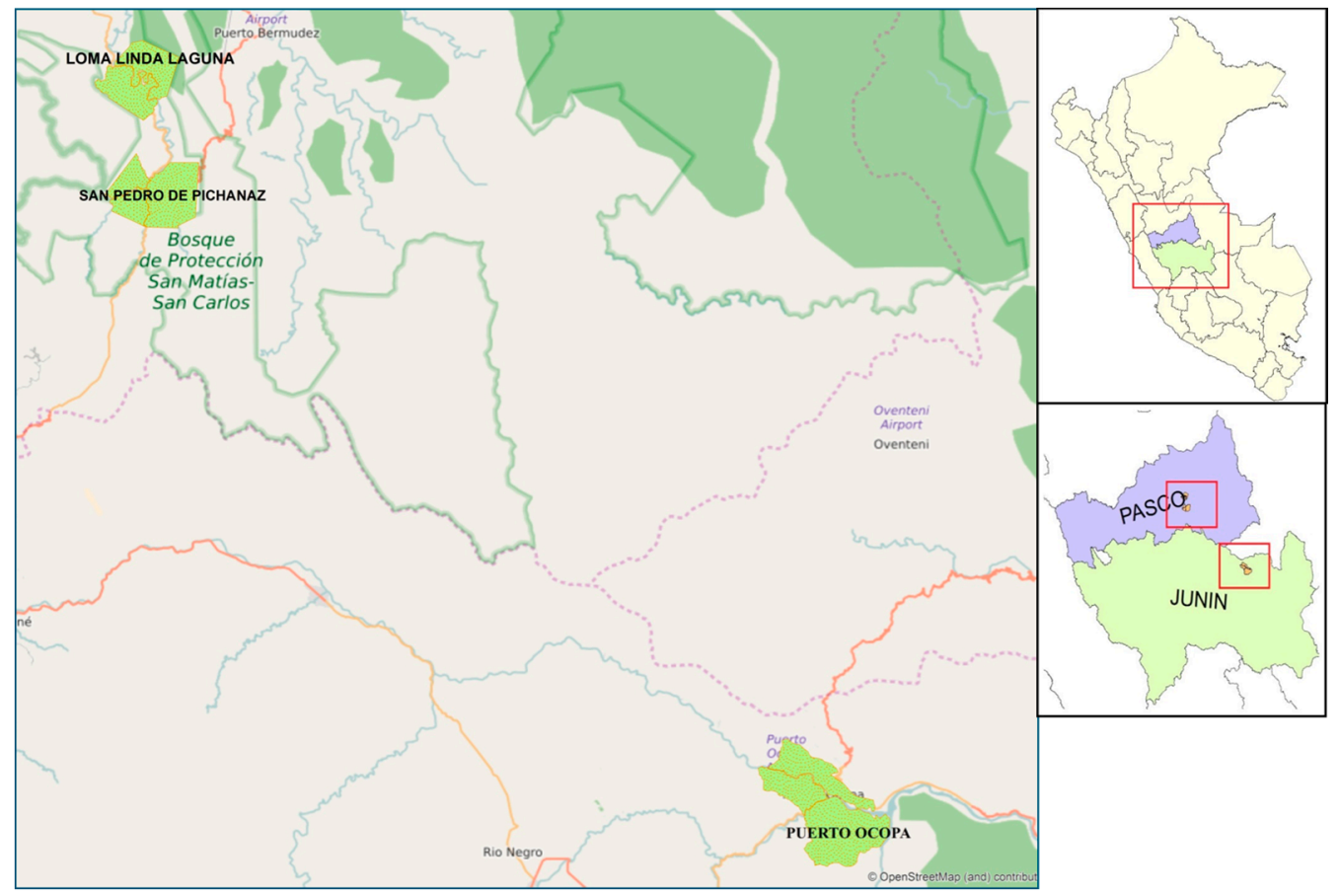

Figure 1. Study area of three communities: Puerto Ocopa, Loma Linda Laguna, and San Pedro de Pichanaz, located the regions of Junín and Pasco, central Peruvian Amazon.

The central Amazon region has experienced several periods of land-use change involving extensive coffee plantations, infrastructure development projects, coca leaf plantations, warfare, and different conservation efforts such as Natural Protected Areas, among others. The community of Puerto Ocopa has the largest area and population and is located in the Satipo province in the Tambo River watershed. The communities of San Pedro de Pichanaz and Loma Linda are in Oxapampa province in the Palcazu River watershed. Whereas Puerto Ocopa is an Ashaninka community, San Pedro de Pichanaz and Loma Linda are both Yanesha communities divided into three sectors based on their location in the territory. However, while all of Puerto Ocopa and all three sectors in San Pedro de Pichanaz are involved in the TDC program and receive benefits, only one sector of Loma Linda is involved. As a result, the size of the conservation areas in the three communities varies (Table 1), which affects the amount of funding disbursed by the PNCB to support local activities.

All communities involved in the TDC program are expected to create a management committee (CG, for its abbreviation in Spanish) and a vigilance (or monitoring) subcommittee (CV, for its 
abbreviation in Spanish) that are both elected by the community's general assembly. The objectives of the CG are to manage the financial compensation from the PNCB for the implementation of its investment plan. The objectives of the $\mathrm{CV}$ are to ensure the integrity and protection of communal forests for conservation through monitoring activities, as well as to prevent and promptly report potential threats to the conservation area. Communities are compensated only if they comply with the agreement, which means they fulfill monitoring responsibilities and address the incidences of deforestation identified through monitoring activities.

\subsection{Assessing Multilevel Institutional Arrangements for Forest Monitoring}

We used multiple methods to gather data. We set out to study the governance of CBM as well as several factors emerging from previous studies [31,33,34] to understand how obstacles to participation in CBM are overcome, given the history of relations between indigenous communities and the state, and the implications for sustainability and potential scalability. The indicators that have been used in the assessment of multilevel governance are shown in Figure 2. Appendix A includes the details of interview questions corresponding to each indicator.

Table 1. General information on the indigenous communities.

\begin{tabular}{cccccc}
\hline Community & Ethnicity & Est. Ppl & Agreement Year & Conservation Area (ha) & TDC Funds (PEN) \\
\hline Puerto Ocopa & Ashaninka & $>1000$ & 2012 & 8030 & $80,300.00$ \\
San Pedro de Pichanaz & Yanesha & 400 & 2012 & 4020 & $40,200.00$ \\
Loma Linda & Yanesha & 700 & 2012 & 2597 & $25,970.00$ \\
\hline
\end{tabular}

Source: Adapted from National Forest Conservation (PNCB, for its abbreviation in Spanish) investment plans for
the three communities [35]. Currency exchange rate $1 \mathrm{PEN}=0.3 \mathrm{USD}$.

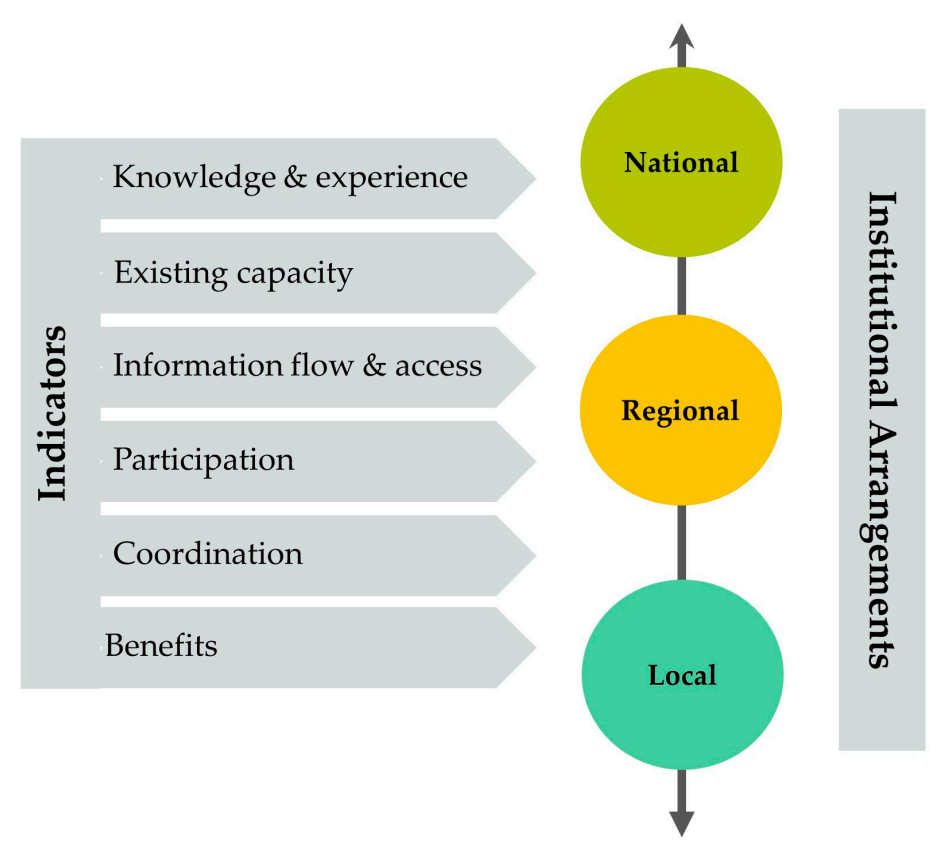

Figure 2. Indicators to assess multilevel governance for forest monitoring.

We used workshops, focus groups, and semi-structured interviews in the three communities to understand the existing governance arrangements for forest monitoring at the national and local levels, as well as the challenges facing CBM and its integration into a multilevel monitoring system. Prior to conducting interviews in each community, the team held workshops to introduce the study, during which information was elicited on the community's background and history and the development of monitoring activities there. Interviews in communities were conducted primarily with CV members in addition to several community members involved in self-defense committees, in the case of Puerto Ocopa, as well as older community members whose experience enabled them to provide input. We then 
conducted semi-structured interviews with the PNCB staff, indigenous organizations, and regional and local government representatives to gauge their knowledge of forest monitoring issues, the TDC program, and the CV's role in the program. The selection of these government officials was based on their position, work with environmental issues, and availability at the time of our research. We also explored the communication patterns and coordination between the TDC program and indigenous federations, as well as local and regional governments. In total, we conducted 56 semi-structured interviews with various key informant types across the three study communities over 16 months in 2015-2016, as part of a project to introduce new handheld, smartphone technology to support ongoing monitoring activities (Appendix B).

As this research was part of a larger project, participant observation was another key aspect of this research. One researcher spent several days in the communities to accompany field activities (up to 10 field trips usually lasting three days each), to better understand uptake and the knowledge acquired on the use of smartphones in forest monitoring and capture perceptions of benefits. All of the data collected was recorded in an Excel database.

\section{Results}

\subsection{Multilevel Institutional Arrangements for Forest Monitoring in Peru}

The research documented the different government institutions at the national, regional, and local levels that hold competencies relevant to forest monitoring in Peru. The results, detailed in Figure 3, suggest that all three levels play an important role. At the time of this research, the regional level was represented not by the regional government authorities but by deconcentrated offices of central ministries of environment and agriculture. Since the time of this research, these offices have been decentralized like in other parts of the country (e.g., the Amazon region).

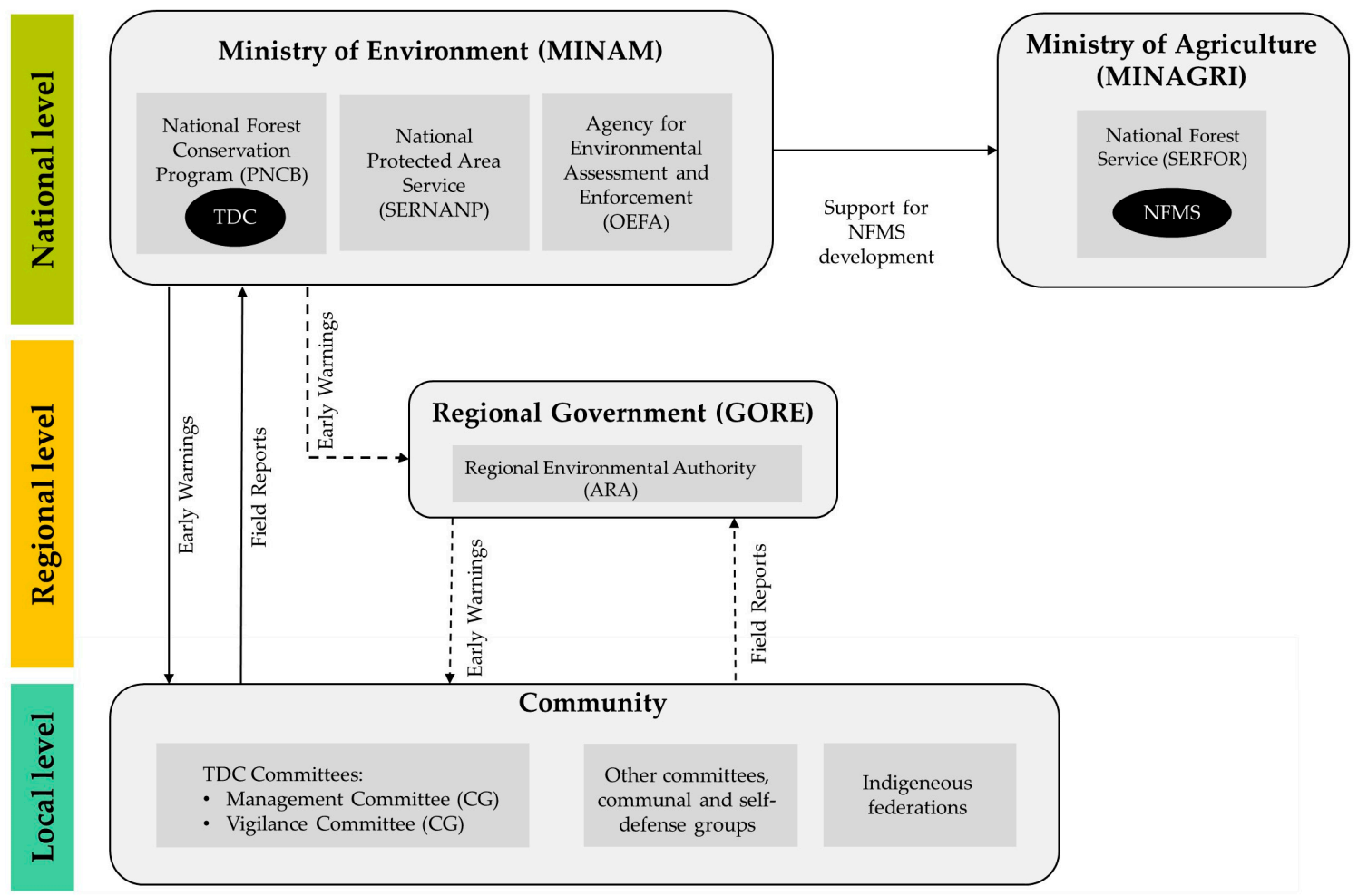

Figure 3. Multilevel institutional arrangements for forest monitoring in Peru. 


\subsection{Drivers of Deforestation}

According to the community monitoring literature, communities are expected to be favorable to monitoring if deforestation and degradation are primarily caused by actors external to the village, and/or if the benefits outweigh the burdens (e.g., the costs of monitoring, the loss of other sources of income or of forest areas for agricultural use). In the former case, the benefits of such a program might include increased community control over territory, while in the latter, they could include access to new sources of income (cash or non-cash) [20]. However, a simple cost-benefit analysis is insufficient.

Through interviews and participant observation, we found that external drivers of deforestation prevailed in the study communities. There is evidence that these drivers partially explain why the communities want to be involved in forest monitoring activities. Informants indicated that the TDC program has helped reduce external threats (i.e., illegal logging, land invasions), as communities feel they have strengthened their capacities around forest (territorial) monitoring.

All of the study communities have problems related to external illegal logging, land invasions, and/or landslides. Informants from Puerto Ocopa stated that loggers often take advantage of legal loopholes and have been working with communities through agreements based on trust and dependency. Given the start-up costs, the loggers develop management plans, obtain harvesting permits, and assume the operational costs. In addition to quantifying the timber and keeping track of accounting, the loggers also gain economically in this relationship. Illegal logging is also widespread in the Palcazu watershed, where Loma Linda and San Pedro de Pichanaz are located. A road near the latter, which cuts through the middle of the San Matías-San Carlos Protected Forest, has been the center of illegal logging, as timber extraction is prohibited in that forest.

Land invasions are also frequent in these communities, particularly by outside farmers, though $\mathrm{CV}$ members interviewed said they have decreased in recent years with the implementation of the TDC program. Meanwhile, landslides, another common cause of deforestation, are common in San Pedro de Pichanaz and Loma Linda due to steep terrain, with their frequency increasing during the rainy season.

CV members reported several internal community deforestation threats. Loma Linda and San Pedro de Pichanaz reported the impact of the cultivation of illegal crops, which, some say, are expected to expand throughout the watershed. Puerto Ocopa faced more threats from land rentals, overlapping land titles, and fires. According to reports from several CV members in Puerto Ocopa, several plots in the community were rented to outside farmers for papaya and citrus cultivation as the result of irregular and often centralized decisions taken by community authorities. The community was supposed to receive a payment for each agreement (e.g., one payment of 1000 Peruvian Soles (PEN) or $\$ 306.58 /$ year for the rental of five to ten hectares), but the benefits were limited, and the farmers usually abandoned the overexploited land before paying their debt. Land titling problems arose as a result of several titling campaigns by different government institutions, resulting in overlapping boundaries with other communities and settlers.

\subsection{Forest Monitoring: Benefit or Burden?}

On their four routine annual trips, CV members collect monitoring data, including a description of the route, coordinates, details on occurrences, and photos. Since the start of the TDC program, the CV has collected data on paper, which is then shared with the local PNCB office. As mentioned, the smartphone application introduced through this project creates a digital data collection platform, including information on who collected the data, where and when this happened, and why the forest cover changed in the areas monitored.

Depending on the monitoring outcomes, the $\mathrm{CV}$ and the community president coordinate with the PNCB for further action. For instance, if community members are found to be clearing forest within the conservation area, the community itself takes action. Conversely, issues like illegal logging, invasions, or the trespassing of community boundaries are coordinated with the PNCB, indigenous organizations, or the relevant forest institution. Meanwhile, trends can be interpreted based on the data 
and used in management decision making. However, we found that the CVs' capacities are limited with respect to data interpretation and, thus, decision-making power based on the data, as they are reliant on the PNCB regional offices for data analysis.

\subsubsection{Financial Incentives}

As mentioned, the TDC program compensates communities 10 PENor $\$ 3.03$ hectare protected in their community. This funding allows them to cover expenses for various activities, including forest monitoring, which require fuel, transportation, food supplies, and equipment. CV members do not receive direct monetary compensation for their efforts, but rather use the money allocated to monitoring activities for their field trips. Eight of the nine CV members interviewed expressed dissatisfaction with the benefits (monetary, food and supplies) that they depend on and use for their field visits for three reasons: the lack of monetary compensation for their time, frequent delays in the disbursement of funds for monitoring activities, and insufficient resources for fulfilling their monitoring responsibilities.

The nine CV members interviewed believe they should receive monetary compensation for their work, primarily because their involvement in monitoring activities involves significant time away from their families and/or income-earning activities. On average, producers have a daily income of 30 PEN or \$10/day. In the words of one CV informant from Loma Linda, "Every day that I'm doing forest monitoring I'm not earning 50 Peruvian soles that I would easily make from the moto-taxi service." Informants reported that in some cases, CV members have not shown up to fulfill their responsibilities because they obtained permanent jobs, such as farming, cocoa plant cultivation, clearing forest in the Palcazu watershed, which pay around 30 or 40 PEN/day, depending on the contractor.

CV members in the communities of Loma Linda and San Pedro de Pichanaz reported delays of up to two to three months in receiving funds and the necessary supplies, which also tends to delay monitoring activities. In Loma Linda, the CV had not received funding for food supplies and new equipment for almost a year at the time of the interviews, while in San Pedro de Pichanaz, the CG allocated funds designated for monitoring field trips to cover the costs of a productive project (grafting cocoa plants). In some cases, delays in disbursement can be explained by insufficient coordination between the CV and the CG, while, in others, the delays come from the PNCB office due to limitations and bureaucratic burdens.

\subsubsection{Training Opportunities}

Although CV members are not compensated monetarily for their work, they do receive training on forest monitoring technologies and techniques, which they find useful across communities. For example, the PNCB trains the communities on Global Positioning System (GPS) use, mapping and reading coordinates, conservation topics, and how to respond to circumstances identified during monitoring (i.e., how to report issues regarding illegal logging, invasions, and other environmental crimes). They receive training at the beginning of the agreement and are then regularly advised by the PNCB technicians and officers. We found that the PNCB has a more significant presence in Puerto Ocopa, where it provides more capacity-building opportunities. Its greater presence there compared to the other two communities may be explained by the mobile phone connection and electricity in the community, its proximity to the city and the PNCB office, and the good state of the road to the community. As previously mentioned, the other communities are divided into sectors, which also makes it more difficult to bring the entire community together due to the distances between them. $\mathrm{CV}$ members interviewed considered that their continued participation was motivated by the training opportunities that enhance their livelihoods, among other reasons.

Three CV members from Puerto Ocopa mentioned having opportunities to earn additional income because of the training sessions they received and their use of new forest monitoring technologies and techniques. For example, CV members from that community reported incidents in which they were paid by small-scale farmers and neighbors to delimit their plots with GPS coordinates. We also 
learned that TDC participants received monetary support for productive activities, but evaluating such benefits was not the focus of this research, as mentioned earlier.

\subsubsection{Local Motivation}

We employ the concept of legitimacy to examine local perceptions around the governance arrangements for CBM at the local level. The particular understanding of legitimacy used is based on a participatory democratic process founded on the participation, transparency, and influence of the various actor groups involved in the monitoring [24]. It is expected that with meaningful participation, stakeholders will develop ownership of negotiated rules and norms over time and are more likely to accept the costs of implementing them [27].

We identified a high level of local motivation, interest, and commitment in terms of participating in monitoring activities across communities. For informants in Puerto Ocopa, interest in participating in monitoring efforts is based on the opportunity to strengthen their capacities in order to protect their territory from environmental threats, a desire to access external resources to cover the costs of community needs, and the pride and sense of belonging or recognition they feel when assuming their monitoring responsibilities. In general, the three communities perceive the alliance with the PNCB as an opportunity to access alternative livelihood options while protecting their territories, given the multiple components included in the program.

According to the PNCB informants from the national and regional offices, local willingness to participate in monitoring activities varies across communities and depends on their past experience (positive or negative) with the state through former state-run programs, their capacity-building opportunities and their desire to reduce pressures from external deforestation drivers. These informants noted a general feeling of community mistrust of the TDC intervention and its conservation goals in the beginning but indicated that this has changed over time. In the words of one indigenous leader, "The PNCB is now more flexible, as its staff are more open to receiving suggestions from indigenous organizations." This leader believed that this might be the first state-run conservation program with multiple goals based on allocating funds for capacity building, social community well-being projects, and generally moving beyond a conservationist vision.

We found that the communities studied are addressing issues related to their own resources, threats, and potentials through their management responsibilities as part of the TDC program. For instance, the CV in San Pedro de Pichanaz once visited a remote part of the conservation area during its monitoring visits and found several large trees with potential for producing valuable timber seedlings. This allowed them to explore opportunities to produce this timber species and integrate it into an agroforestry model with cocoa promoted by the TDC. In Loma Linda, the CV decided to monitor the northern boundary of its territory during the fire season. The purpose was to monitor an old and expansive area of grasslands that borders the community's conservation area, which is where they source timber for domestic use.

Six of the nine CV members interviewed expressed their pride in being a member of the CV, mentioning the significance of the vests they must wear for their field visits. The vests seem to enhance their self-esteem and sense of belonging and importance as they feel recognized by their communities. In addition, CV members also value and are proud of the space and voice they have in the weekly communal assemblies, where they share information related to their work. According to one CV member from San Pedro de Pichanaz, "We work for the sake of the community. The recognition comes with achieving our monitoring goals". Another member from Puerto Ocopa commented that "the community members are satisfied with the little we have done. We have set the community boundaries. It is important to be recognized. Sometimes I walk around with my CV vest and notice that people recognize my position [or duties]". 


\subsection{Legitimacy}

We found that four key factors supported the legitimacy of CBM: (1) a positive, trust-based relationship with the state and, more specifically, a favorable view of the PNCB, (2) the program's engagement with a large portion of the community, rather than a small elite, (3) the compatibility of program requirements with existing governance arrangements, and (4) community interest in the data itself and the ability to use it for local needs. We found that the legitimacy of CBM may be influenced by how well the institutional arrangements being introduced mesh with existing governance arrangements in the communities, as well as the opportunities for participating in monitoring activities and the information flow around them.

\subsubsection{Compatibility with Existing Governance Arrangements}

Evidence points to weaknesses in the $\mathrm{PNCB}^{\prime}$ s recognition of existing local governance arrangements for monitoring in the communities. The three communities studied found different ways to adapt to the new governance structure for monitoring introduced through the TDC program. However, in some cases, an externally introduced monitoring committee led to misunderstanding and confusion due to the overlapping of duties with existing local organizations.

We identified several examples of multiple committees whose monitoring functions often overlap. The Ashaninka communities have local self-defense committees, whose responsibility as a communal policing body is to secure the territory and protect community members from harm. Recognized as the Ashaninka army by Supreme Decree No. 741 [36], they gained recognition from the national government for their activities to protect their territory and people during the conflict between the Peruvian army and the guerrilla organization Shining Path [37]. The Yanesha communities have the Arkanth, which is recognized as a communal police body responsible for ensuring law and order in the area, including the enforcement of sanctions for internal issues such as robbery or crime in the village.

Puerto Ocopa is an example of the community merging its local committee, or CAD, with the $\mathrm{CV}$. In this case, those involved in the two committees managed to integrate their leadership, which added to the legitimacy of the $\mathrm{CV}$ and its monitoring activities. The CAD has its own organizational structure, rules, and channels for reporting alerts or threats related to a community's territory. When threats are detected, the head of the CAD meets with the community president and sends documents to neighboring communities. A group of about 15 individuals and one $\mathrm{CV}$ member then goes out to patrol the area. There is frequent coordination and information sharing between CAD members and the rest of the community through communal assemblies. Actions are also regularly coordinated with the army and marine forces in the case of warnings or threats from the Shining Path, which is now linked to drug trafficking in surrounding areas.

Meanwhile, frequent confusion was reported in communities located in the buffer zone of a national protected area. Such communities have two monitoring committees, one through the TDC that depends on the PNCB and one for the protected area that responds to the National Natural Protected Areas Service (SERNANP). The CV and community monitors for Natural Protected Areas have very similar responsibilities in these communities. Monitoring activities in a protected area involve routine and extraordinary patrols, with the former carried out on a monthly basis and the latter occurring once or twice a year, depending on need. The community monitors are elected in a general assembly and recognized by SERNANP as volunteers to conduct field patrols with official park rangers. Data are collected on threats to forest cover change in protected areas, including illegal logging, illegal crops such as coca plantations, expansion of the agricultural frontier, land invasions, and road building. Even if their respective areas of operation are clearly defined, CV members and community monitors in San Pedro de Pichanaz and Loma Linda reported misunderstandings over who represents the community in forest monitoring matters and how to report detected cases of forest cover change or environmental crimes. 


\subsubsection{Local Participation and Transparency}

We found that participation in monitoring activities is limited to a few individuals, which affects access to information about monitoring, relevant environmental threats or issues, and capacity-building opportunities. Although members are elected by community residents in communal assemblies, not everyone can stand for election, as women and elders are excluded from the selection process. We also found that not everyone wants to participate and some consider it a waste of time, which may also relate to the limited information shared with community members, meaning they are less informed about the CV and less likely to be interested. CV members, who are typically 25- to 30-year-old males, consider that women and elders are also not the most appropriate people to endure the conditions faced during forest monitoring, which usually occurs in areas that are somewhat difficult to access and require considerable physical activity. Women do, however, take part in other local monitoring initiatives, including the previously-mentioned Arkanth or Yanesha community security committees.

There is also a lack of information dissemination between the $\mathrm{CV}$ and the community at large or those not directly engaged in monitoring. Evidence from this and other research studies indicates that community members not involved in the TDC program are unfamiliar with how it really works [38]. CV members across study communities have stated that they tend to withhold some information at times, as they do not want to confuse community inhabitants, given the country's unfamiliarity with both the concepts involved and the TDC program. Interviews with community members and direct observation in communal meetings revealed that members of the community tend to be unfamiliar with the environmental terms and concepts used by the CV and therefore fail to understand or retain the information. On the other hand, in the case of Puerto Ocopa, they are familiar with terms used by its local CAD. Another observation is that the PNCB only trains CV members on concepts and monitoring techniques and does not provide learning opportunities to those outside of the CV.

We found just one case of centralized leadership in San Pedro de Pichanaz, where the community decided that the community president should serve as the president of both the CV and the CG. This was a communal decision triggered by the lack of communication between the two committees when they first joined the TDC program. Both CV and CG members reported that communication had been difficult. However, in the second year of this research, the communal authorities changed, and coordination between the new community president and the TDC committees declined, resulting in delayed monitoring activities and confusion among CV and CG members. In the words of one community member, "This experience demonstrates the importance of the stability of local leadership in shaping the legitimacy of the arrangement."

Based on interviews and participant observation in Puerto Ocopa, we found clear communication patterns around monitoring activities across communities. Information flows from the CV to the community president and then on to the community in communal assemblies. In the case of environmental threats, the CV reports them to the community head and then, if necessary, to the indigenous organization or the relevant government forest institution. The CV is expected to maintain frequent communication with the $C G$, the community president, and the local monitoring entities, such as the CADs. Community members outside the CV report any issues to that committee, which then reports them to the president, after which the president reports to the indigenous federation. This locally-understood information channel allows for fluid communication across actors and facilitates information sharing, even in the face of local leadership challenges. Overall, from the perspective of both the PNCB and the communities, the TDC program has decreased the threat of invasion, promoted conservation awareness, and empowered people to protect their land.

\subsection{Coordination and Scaling Up}

Evidence suggests that communities are choosing to engage and see their participation positively despite not getting many benefits and being monitored by the state. Our findings have uncovered several factors that may influence the potential scale-up of CBM to systems like MRV and the NFMS. These factors include how the PNCB selects and coordinates its work with participating communities, 
the involvement of and coordination with local and regional governments and other government entities in the program, and the coordination of the different actors involved in monitoring.

Informants from the PNCB expected regional governments to play an instrumental role in the TDC program. The head of the PNCB's Forest Monitoring Office believes the regional governments are essential to the TDC operation and the coordination of efforts from national and local levels. The PNCB envisions the regional governments providing the service that the PNCB currently provides to the communities. The PNCB also intends the regional environmental authorities and the regional governments to assume the lead in implementing the Geobosques forest monitoring platform, which is an online tool that tracks forest cover change in the country on a weekly basis and is accessible to the public. Geobosques was released in 2018 and is expected to facilitate the involvement of regional governments in the National Forest Monitoring System. Information sharing across government levels is expected to increase along with different actors' involvement in and use of the Geobosques tool. This tool may make it more feasible for data collected by the CV to reach the regional governments and to integrate that data into the MRV and National Forest Monitoring systems.

To date, the Junín and Pasco regional governments are in the process of creating their respective regional environmental authorities. Both regional governments have developed a regional environmental information system, which is a technological, institutional, and human integration network that facilitates the systematization of, access to, and distribution of environmental information within their regions, as well as its use and sharing to support decision making and environmental management. Although responsibilities have been transferred to the regional governments, this does not imply that they have the human resources or capacity (i.e., staff infrastructure and financial resources) to exercise them [39].

\section{Discussion}

\subsection{Why, or Under What Conditions, Do Communities Support CBM?}

Despite the historical context of difficult relations between the state and indigenous communities, the three study communities maintain a high level of motivation and commitment to the TDC program. There are a few caveats, however, including the insufficient financial incentives. Communities voluntarily join the TDC and have great expectations about how they will benefit from their relationship with the state through that program. We hypothesized that key factors affecting community interest include the source or drivers of deforestation and degradation and the perceived balance of benefits and burdens. We also considered factors contributing to the legitimacy of the program's implementation.

First, the drivers of deforestation are mostly external, so the program's restrictions on community members' land-use practices are minimal or non-existent, and the protection it provides against external land-use threats is considered beneficial. Participants perceive the PNCB as an ally in protecting their territories from external threats, which include illegal logging, invasions, and overlapping titles. In addition, the history of terrorism in the area emphasizes the importance of state support in ensuring territorial security.

Second, evidence suggests that although participants do not receive monetary compensation for their efforts, the capacity building for monitoring and the funds received to support productive activities on participants' farms do seem to provide an important incentive for participation. Local communities are also now engaged in dialogue with the $\mathrm{PNCB}$, as the program is open to suggestions from the organizations.

In general, then, the benefits appear to outweigh the burdens as the program provides important support for confronting external threats and serves to empower communities to protect their territories. Local interest and commitment to the program are demonstrated by the pride involved, as monitors value local and national recognition of their work. CV members gained greater pride with the introduction of smartphone devices in the three communities and were interested in learning more and practicing how to use them. Despite the implied burdens of local participation, participants expressed 
their interest in collaborating with the PNCB and their expectations in terms of program benefits. The mere opportunity to collaborate with the government and negotiate benefits seems to represent an important advantage that is contrasted with the history of indigenous-state relations. In this way, local motivation to access alternative livelihoods options while protecting local territories provide a key source of support for CBM.

In addition, these findings support those of Ekowati et al. [12] in a study on participatory monitoring and reporting in the health sector in Indonesia, suggesting that community recognition, status within the system, training opportunities, and small payments provide incentives to sustain participation. These authors found that a sense of ownership and pride appears particularly valuable and that such motivations have sustained effective participation despite limited financial incentives and external oversight.

Participants' perceptions of benefits vary across communities, however. Findings suggest that, compared to those in the other two communities, CV members in Puerto Ocopa perceived benefits to be more significant, as they receive more capacity-building opportunities from the PNCB and have existing organizations dedicated to territorial security. In Loma Linda and San Pedro de Pichanaz, the CVs have great capacities, but the distance from the PNCB office, the absence of a telephone connection, and the dispersed location of the different sectors in each of the communities limit their access to capacity-building opportunities. Importantly, delays in the disbursement of funds for monitoring and the insufficient benefits distributed to the communities have affected local satisfaction and perceptions of benefits and could potentially affect local trust.

The conservation agreements discussed prohibit communities from clearing forest for agricultural purposes, and the PNCB can suspend or terminate communities' participation in the program if they fail to uphold their end of the agreement. To date, such agreements have not resulted in a fine. While livelihood activities vary across indigenous communities, agricultural production is an important source of income in the communities studied. Nevertheless, CV members interviewed did not perceive the program to be imposing restrictions on activities but rather felt it helped communities defend their territory. Over time, the relationship between the PNCB and the communities became stronger as the latter was promised and received greater resources through their involvement in the program, helping to explain communities' support and general satisfaction. As the three study communities represent those in which the PNCB has invested more resources, they are also likely to be more satisfied than those that have received less resources.

A community-based approach to monitoring is considered more sustainable when local benefits outweigh the costs of local participation and when community monitoring is already embedded in the local community and serves the interests of that community [13,38,40,41]. Danielsen et al. [42] find that if local benefits are not enough to cover the participation costs, monitoring will not occur. Bellfield et al. [38] also suggest that community members undertaking this work should receive financial compensation and argue that relying on community reciprocity or participation alone does not match the opportunity costs of engaging in more attractive economic activities. Given that this issue was mentioned frequently in the communities, it may be a concern for the program's future sustainability.

Third, several factors have built up the program's legitimacy over time. The evidence suggests that trust and greater mutual understanding has been built between state actors involved in the PNCB and the indigenous communities. This is apparent in Puerto Ocopa in particular, where engagement has taken place over a longer period and been more substantial. Nevertheless, there is some risk even in this community because capacity-building opportunities are limited to young (25-30-year old) men involved in the $\mathrm{CV}$, and there is limited information sharing on monitoring activities with the community at large. While the information on the status of monitoring activities is shared by $\mathrm{CV}$ members in communal assemblies, this is limited in practice by their concern that community members will not understand the language used or other concepts related to conservation. Part of the PNCB's work with communities could be to ensure information flow around the TDC program and to hold $\mathrm{CV}$ members accountable for informing their communities of relevant and important monitoring 
activities. On the other hand, attention to community jobs for youth could provide an incentive against out-migration, a huge issue in many indigenous communities today.

Compatibility with existing governance arrangements has played out in different ways in each community and has resulted in some overlap and confusion over roles and authority. This will be discussed in the next subsection. With regard to the use of the data, findings highlight the importance of local participants having the opportunity to integrate their local needs into the monitoring activities in order to collect relevant and useful data that will be of use to them both in the present and the future. For instance, $\mathrm{CV}$ members can decide where to conduct their routine monitoring visits based on what they hear about threats (invasions, logging), the time (days) they have, the availability of transport (if they have to walk long distances or can go by car or motorbike), and the time between visits. In other words, the communities can conduct routine monitoring where they see fit, providing them with the chance to shape the monitoring activities at the local level. Communities do not, however, have a say in what they monitor when the PNCB sends them early warnings nor do they currently have the capacity to analyze the data for local use without PNCB support. Strengthening local capacities and empowering communities to respond to environmental threats are therefore seen as critical.

The TDC program's focus on conservation and its limited alternative livelihood options could risk weakening its potential to capture and sustain local interest. A variety of local and forest resources such as crops, wildlife, fisheries, and non-timber forest products could be integrated into a monitoring and compensation scheme to support sustainability once the TDC program ends. In the words of one protected area officer, "the PNCB is focused on compensating productive activities by introducing new crops, such as coffee and cocoa, rather than sustainable natural resource management already existing within forest [that has] great potential..." In order to make these schemes more economically feasible, it is important for these resources to have a significant local and market value in order to provide alternative sources of income, which would ideally encourage local participation in and commitment to the program in the long run. Furthermore, McCall et al. [43] point out that monitoring efforts that are officially recognized and even monetarily supported can be an incentive for young people to stay in the community and assume a variety of leadership roles.

\subsection{How Can CBM Contribute to a National Forest Monitoring System?}

We found that several factors support or detract from the potential scalability of CBM to Peru's National Forest Monitoring System. First, we identified some confusion around the proliferation of different monitoring committees, including through the TDC program, protected areas, and those already existing in indigenous communities. The overlapping nature of these different governance arrangements has generated some confusion both at the community level and the national institutional level. The current scenario of multiple and sometimes overlapping monitoring entities and the introduction of new monitoring arrangements that do not coordinate with existing ones could reshape local structures and power arrangements within the community, or even lead to misunderstandings and conflict associated with local enforcement. Confusion within communities (with members not in the CVs) about their role in and jurisdiction for forest monitoring was mentioned in the Palcazu communities. The challenges experienced in the communities studied provide reasons to question the replicability of the program in a range of communities that do not meet the ideal conditions discussed throughout this paper.

There are several opportunities for the PNCB to remedy these issues. One is to make efforts to recognize existing monitoring or relevant committees as it supports the community in implementing the program's committees. Another is to involve the strategic actors discussed above to prevent local confusion and conflict. For instance, SERNANP has a presence in six protected areas, and the TDC program involves many communities in their buffer zones, making it necessary to strengthen their coordination through a shared agenda. There is already coordination between two of these areas and the PNCB regarding local forest monitoring, but this only emerged when the actors mentioned 
realized that their interventions were complementary. Prior to this, each institution worked on building capacities for its own committees.

The limited coordination between the PNCB and regional and local governments has also become problematic as regional governments have relevant competencies in the environment and forest sectors and are expected to play an important role in the NFMS.. CBM does not occur in a vacuum, and, if it is to be incorporated into a multilevel monitoring system, the PNCB must work to align the TDC program with regional environmental strategies and thus engage regional governments in the program itself. The existence of the various forest monitoring entities discussed necessitates their coordination and the standardization of certain aspects of forest monitoring. Regional participation could also support the institutionalization of the system and the use of data in regional and local decision making.

The fact that support from indigenous organizations is perceived as important in terms of institutionalizing monitoring activities makes it essential to analyze the role they could have in a multilevel forest monitoring system. For example, a large indigenous federation in the region does not have a specific programmatic focus on forest monitoring but has always spearheaded the defense and protection of the Ashaninka peoples' territories and forests. It is also important to highlight the several indigenous organizations affiliated with the federations that are already involved in CBM since they are the co-managers of these areas. As such, they have developed specific capacities and knowledge that could be instrumental in the coordination of the TDC's efforts or work with the indigenous sector. However, the outcomes of the TDC program are uncertain. Not all the communities involved are fully engaged, nor do they all have the same response to a state-run forest monitoring program. Consistency, transparency, comparability, completeness, and accuracy of data are not achieved overnight.

Other strategic actors that could encourage the incorporation of CBM into a multilevel monitoring system include institutions with competencies in the forest and environment sectors, including the National Forest Service (SERFOR), Environmental Inspection and Assessment Agency (OEFA), and the Forest Resources Oversight Agency (OSINFOR). Even if the decentralization of responsibilities in the forest sector is still in progress in the Junín and Pasco regions, the Indigenous People's Affairs from the Pasco Regional Government and offices of Environmental Management could take the lead in CBM through the TDC program. Information sharing will only become fluid once these different actors begin coordinating and have a clear understanding of their roles within the system, which will then also enable the effective scale-up of local monitoring efforts to a multilevel forest monitoring system.

\section{Conclusions}

As the global scenario evolves on climate issues, multilevel forms of governance are being incorporated into planning and policymaking. Opportunities exist for the integration of CBM into a multilevel monitoring system that will support the NFMS and REDD+ MRV systems under development to create reliable and accurate sources of data. As with any intervention, there is concern about the culmination of the program and the discontinuation of the institutions and practices put in place. At the same time, the context of the new forest legislation that creates monitoring mechanisms and different entities with similar responsibilities located at different levels also creates concern regarding potential legitimacy issues. This legislation also generates confusion over the roles of existing institutions among community members and others involved in monitoring activities. The three best cases presented in this paper have overcome some of these barriers, but evidence suggests that the state needs to approach communities with openness and willingness to learn, adapt, build trust, and negotiate in the development and implementation of programs.

This study also draws attention to the importance of placing value on local participation in conservation and understanding the costs of local community involvement in activities that take members away from their daily activities. Conservation programs that involve local communities in activities to protect forests and monitor areas to reduce threats to their territories and conservation areas have more recently begun to incorporate compensation mechanisms. Questions regarding what benefits are distributed and how this is done have become central to low emission rural development 
initiatives. Skutsch et al. [6] underscore the link between the benefit distribution system and CBM activities. They recommend that countries interested in promoting CBM as part of the monitoring for REDD+ should consider how benefits are distributed at different levels by actors involved in monitoring and provide protocols for CBM efforts that meet these requirements.

Furthermore, engaging communities in the design and implementation phases of incentive-based conservation programs is critical to their overall legitimacy [44], as these decisions may affect livelihoods, rights, or territory [45]. Given the history of past government-led programs that were more authoritative and less participatory in nature, incentive-based programs can be understood as an exercise of power or social control [45]. Importance has been and should continue to be placed on community engagement in a way that promotes legitimacy, the program's resilience and adaptive capacity in the long run [10,46,47], and the transformation of power relations over time [48]. It is, therefore, important that external actors understand and engage with the priorities of local communities [49-51].

The findings in this paper are limited to three cases where TDC invests greater resources-in what the program considers high performing communities. Hence, the challenges discussed would likely require even greater efforts and resources from the PNCB in communities considered lower performing. Variations related to the TDC's efforts in building capacities, providing a reliable source of resources for monitoring activities, and relatedly, building trust, are important considerations in assessing the sustainability and scalability of the program. In this way, future studies could capture the diversity of perceptions presented in other lower-performing communities to consider what it would take to overcome these challenges and build legitimacy over time.

Author Contributions: L.F.K., A.K.P., A.M.L. and M.H. conceived and designed the study, A.P.O.d.A. carried out the fieldwork; A.P.O.d.A. and L.F.K. analyzed the data; L.F.K., A.K.P., and A.P.O.d.A. wrote the paper; A.M.L. and C.B. provided substantial comments and edits on different drafts; M.H. reviewed the paper. All authors have read and agreed to the published version of the manuscript.

Funding: This research is part of CIFOR's Global Comparative Study on REDD+ (Norway/NORAD Grant Agreement \#QZA-10/0468) and with financial support from the donors to the CGIAR Fund. Further support is provided by USFS/Silvacarbon Peru project (Grant Agreement \#18-IG-11132762-374), the Consultative Group on International Agricultural Research programs on Trees, Forests and Agroforestry (FTA), and the German BMBF IKI Transparent Monitoring project (Project title: 19_III_108_Global_A_Independent Monitoring Land Sector).

Acknowledgments: The authors would like to thank the National Forest Conservation Program for its time, in particular Gustavo Huamani, Jorge Tito, and Ruben Jacinto. We also thank all key informants from the local and regional governments, SERNANP, SERFOR, and GIZ. We are especially grateful to all of the local informants from the indigenous communities of Puerto Ocopa, Loma Linda, and San Pedro de Pichanaz, who shared their time and knowledge of forest monitoring and the TDC program with us. We thank Silva Carbon and USAID for the support that made this research possible.

Conflicts of Interest: The authors declare no conflict of interest. The founding sponsors had no role in the design of the study; in the collection, analyses, or interpretation of data; in the writing of the manuscript, or in the decision to publish the results.

Appendix A. Indicators and Interview Questions

\begin{tabular}{lll}
\hline \multicolumn{1}{c}{ Indicators } & \multicolumn{1}{c}{ Questions } \\
\hline Existing knowledge and experience of forest monitoring & - & Drivers of deforestation and forest degradation: What, when, where, how? \\
\hline & - & How do actors use the data collected from monitoring? \\
\hline Existing capacity to conduct forest monitoring & - & What have you learned from being involved in monitoring? \\
& - & What training or capacity building has been or is expected to be done? \\
& - & What challenges have you experienced in fulfilling monitoring activities?
\end{tabular}




\begin{tabular}{|c|c|c|}
\hline Participation & - & $\begin{array}{l}\text { Are all stakeholders involved that should be involved in forest monitoring } \\
\text { activities? If not, why are those actors not involved? And who else should } \\
\text { be involved? }\end{array}$ \\
\hline Coordination & - & What coordination is there between committees (CV-CG)? \\
\hline Information flow/access to information & - & $\begin{array}{l}\text { How is information about monitoring shared with communities? What } \\
\text { kind of information? } \\
\text { How do different actors involved in forest monitoring communicate? }\end{array}$ \\
\hline Benefits & - & $\begin{array}{l}\text { What are the benefits of participating in monitoring activities? } \\
\text { Do these benefits compensate you for the time and effort put } \\
\text { into monitoring? }\end{array}$ \\
\hline
\end{tabular}

\section{Appendix B. Interviews by Type of Key Informant}

\begin{tabular}{|c|c|c|c|}
\hline Number of Informants & Type of Informant & Affiliation & Date \\
\hline 20 & Key CBM informants & $\begin{array}{l}\text { CV members and members of } \\
\text { other local organizations }\end{array}$ & $\begin{array}{l}1 / 2015 \\
2 / 2016\end{array}$ \\
\hline 8 & $\begin{array}{l}\text { Key local- and regional-level } \\
\text { government informants }\end{array}$ & 2 regional; 3 provincial; 3 local & $3 / 2016$ \\
\hline 8 & Key community-level informants & $\begin{array}{c}\text { Indigenous community } \\
\text { presidents, community members }\end{array}$ & $1 / 2015 ; 3 / 2016$ \\
\hline 9 & Key informants-PNBC staff & $\begin{array}{l}3 \text { PNCB-TDC national staff; } 6 \text { local } \\
\text { PNCB officers }\end{array}$ & $1 / 2015 ; 3 / 2015 ; 3 / 2016$ \\
\hline 6 & Key CBM informants in the regions & $\begin{array}{l}4 \text { natural protected areas } \\
\text { (SERNANP); } 2 \text { forest institutions } \\
\text { (SERFOR, OSINFOR) }\end{array}$ & $3 / 2016 ; 4 / 2016$ \\
\hline 5 & $\begin{array}{l}\text { Key CBM informants from } \\
\text { indigenous institutions }\end{array}$ & $\begin{array}{c}3 \text { indigenous federations; } \\
2 \text { indigenous SERNANP } \\
\text { community monitors }\end{array}$ & $1 / 2015 ; 3 / 2016$ \\
\hline 56 & & Total & \\
\hline
\end{tabular}

\section{Abbreviations}

ARA Regional Environmental Authority (Autoridad Regional Ambiental)

CAD Self-Defense Committee (Comité de Autodefensa Civil)

CBM Community-Based Monitoring

CG Management Committee

CV Vigilance Committee 4

CVCFC Forest Community Monitoring and Oversight Committee (Comité de Vigilancia y Control Forestal Comunitaria)

GORE Regional Government (Gobierno Regional)

MINAGRI Ministry of Agriculture and Irrigation (Ministerio de Agricultura y Riego)

MINAM Ministry of Environment (Ministerio del Ambiente)

MRV Monitoring, Reporting and Verification

NFMS National Forest Monitoring System

OEFA Agency for Environmental Assessment and Enforcement (Organismo de Evaluación y Fiscalización Ambiental)

OSINFOR Forest and Wildlife Resources Supervisory Agency (Organismo de Supervisión de los Recursos Forestales y de Fauna

$\begin{array}{ll}\text { OSINFOR } & \text { Silvestre) } \\ \text { PES } & \text { Payment for Environmental Services }\end{array}$

PNCB National Forest Conservation Program (Programa Nacional de Conservación de Bosques)

REDD+ Reducing emissions from deforestation and forest degradation, and the role of conservation, sustainable management REDD+ and enhancement of forest carbon stocks in developing countries

SERFOR National Forest and Wildlife Service (Servicio Nacional Forestal y de Fauna Silvestre)

SERNANP Peruvian National Protected Areas Service (Servicio Nacional de Áreas Protegidas por el Estado)

TDC Conditional Direct Transfers (Transferencias Directas. Condicionadas). 


\section{References}

1. UNFCCC. Methodological Guidance for Activities Relating to Reducing Emissions from Deforestation and Forest Degradation and the Role of Conservation, Sustainable Management of Forests and Enhancement of Forest Carbon Stocks in Developing Countries, Decision: 4/cp.15. In Proceedings of the UNFCCC COP 15, Copenhagen, Denmark, 7-18 December 2009.

2. Luttrell, C.; Loft, L.; Gebara, M.F.; Kweka, D.; Brockhaus, M.; Angelsen, A.; Sunderlin, W.D. Who should benefit from redd+? Rationales and realities. Ecol. Soc. 2013, 18, 52. [CrossRef]

3. Vijge, M.J.; Brockhaus, M.; Di Gregorio, M.; Muharrom, E. Framing national Redd+ benefits, monitoring, governance and finance: A comparative analysis of seven countries. Glob. Environ. Chang. 2016, 39, 57-68. [CrossRef]

4. Angelsen, A. Redd+ as result-based aid: General lessons and bilateral agreements of norway. Rev. Dev. Econ. 2017, 21, 237-264. [CrossRef]

5. Maniatis, D.; Scriven, J.; Jonckheere, I.; Laughlin, J.; Todd, K. Toward redd+ implementation. Annu. Rev. Environ. Resour. 2019, 44, 373-398. [CrossRef]

6. Skutsch, M.; Turnhout, E.; Vijge, M.; Herold, M.; Wits, T.; den Besten, J.; Torres, A. Options for a national framework for benefit distribution and their relation to community-based and national redd+ monitoring. Forests 2014, 5, 1596-1617. [CrossRef]

7. Boissière, M.; Beaudoin, G.; Hofstee, C.; Rafanoharana, S. Participating in redd+ measurement, reporting, and verification (pmrv): Opportunities for local people? Forests 2014, 5, 1855-1878.

8. Pratihast, A.; DeVries, B.; Avitabile, V.; de Bruin, S.; Kooistra, L.; Tekle, M.; Herold, M. Combining satellite data and community-based observations for forest monitoring. Forests 2014, 5, 2464-2489. [CrossRef]

9. Pratihast, A.K.; Herold, M.; De Sy, V.; Murdiyarso, D.; Skutsch, M. Linking community-based and national redd+ monitoring: A review of the potential. Carbon Manag. 2013, 4, 91-104. [CrossRef]

10. Danielsen, F.; Burgess, N.; Funder, M.; Blomley, T.; Brashares, J.; Akida, A.; Jensen, A.; Mendoza, M.; Stuart-Hill, G.; Poulsen, M.K. Taking stock of nature in species-rich but economically poor areas: An emerging discipline of locally based monitoring. In Taking Stock of Nature: Participatory Biodiversity Assessment for Policy, Planning and Practice; Cambridge University Press: Cambridge, UK, 2010; Volume 5, pp. 88-112.

11. Somorin, O.A.; Visseren-Hamakers, I.J.; Arts, B.; Sonwa, D.J.; Tiani, A.-M. Redd+ policy strategy in cameroon: Actors, institutions and governance. Environ. Sci. Policy 2014, 35, 87-97. [CrossRef]

12. Ekowati, D.; Hofstee, C.; Praputra, A.V.; Sheil, D. Motivation matters: Lessons for redd+ participatory measurement, reporting and verification from three decades of child health participatory monitoring in indonesia. PLoS ONE 2016, 11, e0159480. [CrossRef]

13. Larrazábal, A.; McCall, M.K.; Mwampamba, T.H.; Skutsch, M. The role of community carbon monitoring for redd+: A review of experiences. Curr. Opin. Environ. Sustain. 2012, 4, 707-716.

14. Murtagh, C. Shifting strategies: The myth of wanamei and the amazon indigenous redd+ programme in madre de dios, peru. In Indigenous Perceptions of the End of the World; Springer: Berlin/Heidelberg, Germany, 2019; pp. 115-139.

15. Peluso, N.L. Rich Forests, Poor People: Resource Control and Resistance in Java; Univ of California Press: Berkeley, CA. USA, 1992; p. 336.

16. Van Cott, D.L. Indigenous peoples and democracy: Issues for policymakers. In Indigenous Peoples and Democracy in Latin America; Palgrave Macmillan: London, UK, 1995; pp. 1-28.

17. Yashar, D.J. Democracy, indigenous movements, and postliberal challenge in latin america. World Politics 1999, 52, 76-104. [CrossRef]

18. Shankland, A.; Hasenclever, L. Indigenous peoples and the regulation of redd+ in brazil: Beyond the war of the worlds? Ids Bull. 2011, 42, 80-88. [CrossRef]

19. Tappe, O. The Art of not Being Governed: An Anarchist History of Upland Southeast Asia; JSTOR: New York, NY, USA, 2010.

20. Larson, A.M.; Cronkleton, P.; Barry, D.; Pacheco, P. Tenure Rights and Beyond: Community Access to Forest Resources in Latin America; CIFOR: Bogor, Indonesia, 2008.

21. Agrawal, A.; Redford, K. Conservation and displacement: An overview. Conserv. Soc. 2009, 7, 1-10. [CrossRef] 
22. Larson, A.M.; Pulhin, J.M. Enhancing forest tenure reforms through more responsive regulations. Conserv. Soc. 2012, 10, 103-113. [CrossRef]

23. PNCB. Manual de Procedimientos Para la Implementación del Esquema de Transferencias Directas Condicionadas del Programa Nacional de Conservación de Bosques Para la Mitigación del Cambio Climático; PNCB: Peru, Lima, 2011; p. 34 .

24. Ansell, C.; Gash, A. Collaborative governance in theory and practice. J. Public Adm. Res. Theory 2008, 18, 543-571. [CrossRef]

25. Emerson, K.; Nabatchi, T.; Balogh, S. An integrative framework for collaborative governance. J. Public Adm. Res. Theory 2012, 22, 1-29. [CrossRef]

26. Pahl-Wostl, C. A conceptual framework for analysing adaptive capacity and multi-level learning processes in resource governance regimes. Glob. Environ. Chang. 2009, 19, 354-365. [CrossRef]

27. Rantala, S.; Hajjar, R.; Skutsch, M. Multilevel governance for forests and climate change: Learning from southern mexico. Forests 2014, 5, 3147-3168. [CrossRef]

28. PNCB. Protocolo de Vigilancia y Monitoreo de Bosques en Comunidades Nativas de la Zona de Amortiguamiento de la Reserva Comunal Yanesha; PNCB: Iscozacin, Mayo, 2016; p. 47.

29. Pettenella, D.; Brotto, L. Governance features for successful redd+ projects organization. For. Policy Econ. 2012, 18, 46-52. [CrossRef]

30. White, D. A perfect storm? Indigenous rights within a national redd+ readiness process in peru. Mitig. Adapt. Strateg. Glob. Chang. 2014, 19, 657-676. [CrossRef]

31. Yang, A.; Nguyen, D.T.; Vu, T.P.; Le Quang, T.; Pham, T.T.; Larson, A.; Ashwin, R. Analyzing Multilevel Governance in Vietnam: Lessons for Redd+ from the Study of Land-Use Change and Benefit Sharing in Nghe an and Dien Bien Provinces. CIFOR Working Paper. 2016. Available online: https://www.cifor.org/ library/6392/ (accessed on 5 January 2020).

32. Larson, A.M.; Lewis-Mendoza, J. Decentralisation and devolution in nicaragua's north atlantic autonomous region: Natural resources and indigenous peoples' rights. Int. J. Commons 2012, 6, 179-199. [CrossRef]

33. Newig, J.; Fritsch, O. Environmental governance: Participatory, multi-level-and effective? Environ. Policy Gov. 2009, 19, 197-214. [CrossRef]

34. Bartley, T.; Andersson, K.; Jagger, P.; Laerhoven, F.V. The contribution of institutional theories to explaining decentralization of natural resource governance. Soc. Nat. Resour. 2008, 21, 160-174. [CrossRef]

35. Gibson, C.C.; Williams, J.T.; Ostrom, E. Local enforcement and better forests. World Dev. 2005, 33, $273-284$. [CrossRef]

36. PNCB. Plan Operativo Institucional-II. Reprogramación. Unidad Ejecutora 002 Conservación de Bosques; PNCB: Peru, Lima, 2016; p. 49.

37. Corbera, E.; Schroeder, H. Governing and implementing redd+. Environ. Sci. Policy 2011, 14, 89-99. [CrossRef]

38. Piu, H.C.; Menton, M. The Context of Redd+ in Peru: Drivers, Agents and Institutions; CIFOR: Bogor, Indonesia, 2014; Volume 106.

39. Laplante, L.J.; Theidon, K. Truth with consequences: Justice and reparations in post-truth commission peru. Hum. Rts. Q. 2007, 29, 228. [CrossRef]

40. Bellfield, H.; Sabogal, D.; Goodman, L.; Leggett, M. Case study report: Community-based monitoring systems for redd+ in guyana. Forests 2015, 6, 133-156. [CrossRef]

41. Sheil, D.; Boissière, M.; Beaudoin, G. Unseen sentinels: Local monitoring and control in conservation's blind spots. Ecol. Soc. 2015, 20, 39. [CrossRef]

42. Wong, G.Y.; Luttrell, C.; Loft, L.; Yang, A.; Pham, T.T.; Naito, D.; Assembe-Mvondo, S.; Brockhaus, M. Narratives in redd+ benefit sharing: Examining evidence within and beyond the forest sector. Clim. Policy 2019, 19, 1038-1051. [CrossRef]

43. Danielsen, F.; Burgess, N.D.; Balmford, A. Monitoring matters: Examining the potential of locally-based approaches. Biodivers. Conserv. 2005, 14, 2507-2542. [CrossRef]

44. McCall, M.K.; Chutz, N.; Skutsch, M. Moving from measuring, reporting, verification (mrv) of forest carbon to community mapping, measuring, monitoring (mmm): Perspectives from mexico. PLoS ONE 2016, 11, e0146038. [CrossRef] [PubMed]

45. Herold, M.; Skutsch, M.M. Monitoring, reporting and verification for national REDD+ programmes: Two proposals. Environ. Res. Lett. 2011, 6, 1. [CrossRef] 
46. Grant, R.W. Strings Attached: Untangling the Ethics of Incentives; Princeton University Press: Princeton, NJ, USA, 2014.

47. Awono, A.; Somorin, O.A.; Atyi, R.E.A.; Levang, P. Tenure and participation in local redd+ projects: Insights from southern cameroon. Environ. Sci. Policy 2014, 35, 76-86. [CrossRef]

48. Wilson, N.J.; Mutter, E.; Inkster, J.; Satterfield, T. Community-based monitoring as the practice of indigenous governance: A case study of indigenous-led water quality monitoring in the yukon river basin. J. Environ. Manag. 2018, 210, 290-298. [CrossRef] [PubMed]

49. Krause, T.; Nielsen, T.D. The legitimacy of incentive-based conservation and a critical account of social safeguards. Environ. Sci. Policy 2014, 41, 44-51. [CrossRef]

50. Pokorny, B.; Scholz, I.; De Jong, W. Redd+ for the poor or the poor for redd+? About the limitations of environmental policies in the amazon and the potential of achieving environmental goals through pro-poor policies. Ecol. Soc. 2013, 18, 3. [CrossRef]

51. Rival, L.M. From carbon projects to better land-use planning: Three latin american initiatives. Ecol. Soc. 2013, 18, 17. [CrossRef]

(C) 2020 by the authors. Licensee MDPI, Basel, Switzerland. This article is an open access article distributed under the terms and conditions of the Creative Commons Attribution (CC BY) license (http://creativecommons.org/licenses/by/4.0/). 